\title{
On the ship course-keeping control system design by using robust feedback linearization
}

\author{
Zenon Zwierzewicz, Assoc. Prof. \\ Maritime University of Szczecin, Poland
}

\begin{abstract}
In the paper the problem of ship autopilot design based on feedback linearization method combined with the robust control approach, is considered. At first the nonlinear ship model (of Norrbin type) is linearized with the use of the simple system nonlinearity cancellation. Next, bearing in mind that exact values of the model parameters are not known, the ensuing inaccuracies are taken as disturbances acting on the system. Thereby is obtained a linear system with an extra term representing the uncertainty which can be treated by using robust, $H_{\infty}$ optimal control techniques. The performed simulations of ship course-changing process confirmed a high performance of the proposed controller despite the assumed significant errors of its parameters.
\end{abstract}

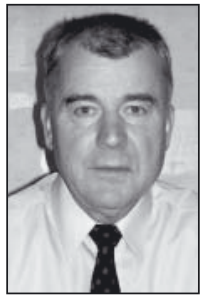

Key words: feedback linearization; robust control; differential games; ship autopilot design

\section{INTRODUCTION}

The feedback linearization (FL) method $[9,10,11,13]$ consists in such transformation of a given nonlinear system which results in a new, linear time-invariant one. Here, by the transformation we mean the application of a proper control law combined with possible change of the system coordinates. Once a linear system is obtained, a secondary control law (or subcontrol) should be designed to ensure that the overall closedloop system performs according to the specifications.

In the simplest case of the system the FL method is reduced to the ordinary cancellation of nonlinearity by means of a properly selected control function.

One of the main drawbacks of FL method relates to inaccuracies arising during cancellation of system nonlinearities. The thereby obtained transformed system is in fact not perfectly linear and, moreover, these imperfections may often prevent the use of efficient techniques of linear systems synthesis. An effective way to solve this problem consists in combination of feedback linearization method with the robust control techniques. In this paper $\mathrm{H}_{\infty}$ optimal control theory within the state space framework is applied, i.e. the problem is considered from position of differential games theory $[4,5,8$, 16]. In this view the model uncertainties are considered as an action of adversary player (or opposing nature) while our part is to invent a control strategy that is the best in terms of some given quality criterion (cost functional). In other words we are trying to minimize the cost assuming the 'worst-case action' of our opponent player (disturbances). Such an approach allows devising a controller which taking into consideration system parametric uncertainties, guarantees at the same time a good process performance.

In the paper, besides presenting a relevant portion of the above stated theory, its usefulness to ship course-keeping (or changing) problem is considered.

It is known that the PID (proportional-integral-derivative) controllers traditionally used in the field still have many shortcomings.

A disadvantage of a PID controller is that it can provide optimal performance only at the operating point for which it is designed. The ship parameters vary significantly with operating conditions such as e.g. forward speed of the vessel. Under the varying operating conditions, is tedious and difficult to determine properly the fixed parameters of the controller that results in good performance. Furthermore, the PID autopilots can cause difficulties when the ship makes large maneuvers involving non-linear dynamic behaviour. To avoid the problems of fixed structure PID autopilots, adaptive autopilots were introduced in the 1970s and have remained a major area of research until now $[2,17]$.

An alternative and promising research direction is the autopilot design from position of robust control theory for nonlinear systems. Therefore the main motivation of this paper is a proposal of the robust ship autopilot design which, based on recent $\mathrm{H}_{\infty}$ theory, is able to finely cope with above mentioned inconveniences.

The paper is divided into five sections and ended with conclusions. The second section presents the system class definitions, basic concepts as well as the transformation of considered system into standard differential game form. In 
the third section a course-keeping problem and the Norrbin's ship model structure are given. In the fourth section the two cases of robust ship autopilot design are presented (with and without load disturbances taken into account). The last, fifth section includes a short description of simulation tests and their results.

\section{BASIC CONCEPTS AND DEFINITIONS} [11]:

Let us consider a nonlinear system in Brunovsky form

$$
\begin{gathered}
\dot{\mathrm{x}}_{1}=\mathrm{x}_{2} \\
\dot{\mathrm{x}}_{2}=\mathrm{x}_{3} \\
\vdots \\
\dot{\mathrm{x}}_{\mathrm{n}}=\mathrm{f}\left(\mathbf{x}, \boldsymbol{\theta}^{\mathrm{f}}\right)+\mathrm{g}\left(\mathbf{x}, \boldsymbol{\theta}^{\mathrm{g}}\right) \mathrm{u} \\
\mathrm{y}=\mathrm{x}_{1}
\end{gathered}
$$

where:

$\mathbf{x} \in \mathbf{R}^{\mathrm{n}} \quad-$ the state vector,

$\boldsymbol{\theta}^{\mathrm{f}} \in \mathbf{R}^{\mathrm{k}}, \boldsymbol{\theta}^{\mathrm{g}} \in \mathbf{R}^{1}-$ vectors of system parameters,

$\mathrm{u} \in \mathbf{R} \quad-$ the control input,

$\mathrm{y} \in \mathbf{R} \quad-$ the system output.

In the case of exact system model, i.e. under assumption that the nonlinear functions fand $g$ of the model (1a) are known (and $\mathrm{g}\left(\mathbf{x}, \boldsymbol{\theta}^{\mathrm{g}}\right) \neq 0, \forall \mathbf{x} \in \mathbf{R}^{\mathrm{n}}$ ) the insertion of the simple output feedback linearizing controller $[9,10,13,18]$ :

$$
\mathrm{u}=\frac{-\mathrm{f}\left(\mathbf{x}, \boldsymbol{\theta}^{\mathrm{f}}\right)+\mathrm{v}}{\mathrm{g}\left(\mathbf{x}, \boldsymbol{\theta}^{\mathrm{g}}\right)}
$$

in the system (1a) results in exact cancellation of both nonlinearities (f and $g$ ), which yields:

$$
\mathrm{y}^{(\mathrm{n})}=\mathrm{v}
$$

To find the control $v(t)$ stabilizing this linear system a standard pole location technique can be used. If $\mathrm{v}$ is chosen as:

$$
\mathrm{v}=-\mu_{\mathrm{r}} \mathrm{y}^{(\mathrm{r}-1)}-\cdots-\mu_{1} \mathrm{y}
$$

and the coefficients $\mu_{\mathrm{i}}$ are such that $\Gamma(\mathrm{s})=\mathrm{s}^{\mathrm{r}}+\mu_{\mathrm{r}} \mathrm{S}^{(\mathrm{r}-1)}+\ldots \mu_{1}$ is a Hurwitz polynomial in the Laplace variable $s$, then the output $y(t)$ and its derivatives converge to zero asymptotically, because the closed-loop dynamics is reduced to the equation:

$$
\mathrm{y}^{(\mathrm{r})}+\mu_{\mathrm{r}} \mathrm{y}^{(\mathrm{r}-1)}+\ldots \mu_{1} \mathrm{y}=0
$$

which, by virtue of the choice of coefficients $\mu_{\mathrm{i}}$ is asymptotically stable. Let's notice that also the internal stability i.e. the state $\mathrm{x} \rightarrow 0$ as $\mathrm{t} \rightarrow \infty$ is obtained.

As the true system parameters $\boldsymbol{\theta}^{\mathrm{f}}, \boldsymbol{\theta}^{\mathrm{g}}$ are unknown and only some their estimates $\hat{\boldsymbol{\theta}}^{\mathrm{f}}, \hat{\boldsymbol{\theta}}^{\mathrm{g}}$ are at our disposal the nonlinear functions of the system (1a) are $\hat{f}\left(\mathbf{x}, \hat{\boldsymbol{\theta}}^{\mathrm{f}}\right)+\hat{\mathrm{g}}\left(\mathbf{x}, \hat{\boldsymbol{\theta}}^{\mathrm{g}}\right) \mathrm{u}$ and the control law (2) takes now the form:

$$
\mathrm{u}=\frac{-\hat{\mathrm{f}}\left(\mathbf{x}, \hat{\boldsymbol{\theta}}^{\mathrm{f}}\right)+\mathrm{v}}{\hat{\mathrm{g}}\left(\mathbf{x}, \hat{\boldsymbol{\theta}}^{\mathrm{g}}\right)}
$$

Since the insertion of the control (6) into the system (1a) no longer guarantees exact cancellation and thereby a resulting system linearity (like in the former case (2)) we will try to solve this problem from position of differential games. To transform our system into a suitable form we perform the following calculations.
Adding to and subtracting from the last equation of the system (1a) the sub-control v we get:

$$
\dot{x}_{n}=\underbrace{f-\hat{f}+(g-\hat{g}) u}_{w}+v
$$

where the formula $v=\hat{f}+\hat{g u}$ obtained from (6) was also used here.

Now denoting $\mathrm{w}=\mathrm{f}-\hat{\mathrm{f}}+(\mathrm{g}-\hat{\mathrm{g}}) \mathrm{u}$ and treating $\mathrm{w}$ as system disturbances we may rewrite the equations (1a) into the general matrix form [3].

$$
\begin{gathered}
\dot{\mathrm{x}}=\mathbf{A x}+\mathbf{B}_{\mathrm{v}} \mathbf{v}+\mathbf{B}_{\mathrm{w}} \mathbf{w} \\
\mathbf{y}=\mathbf{C}_{\mathrm{y}} \mathbf{x}+\mathbf{D}_{\mathrm{yv}} \mathbf{u}
\end{gathered}
$$

where: $\mathbf{A}=\left[\begin{array}{ccccc}0 & 1 & 0 & \cdots & 0 \\ 0 & 0 & 1 & \cdots & 0 \\ \vdots & & & \ddots & \vdots \\ 0 & & & & 1 \\ 0 & 0 & \cdots & 0 & 0\end{array}\right], \mathbf{B}_{\mathrm{v}}=\mathbf{B}_{\mathrm{w}}=\left[\begin{array}{c}0 \\ 0 \\ \vdots \\ 0 \\ 1\end{array}\right]$

$$
\mathbf{D}_{\mathrm{yv}}^{\mathrm{T}} \mathbf{C}_{\mathrm{y}}=\mathbf{0}, \mathbf{D}_{\mathrm{yv}}^{\mathrm{T}} \mathbf{D}_{\mathrm{yv}}=\mathbf{I}
$$

Let's observe that for optimization purposes a new output, $(8 b)$, is defined.

The matrices $\mathbf{C}_{\mathrm{y}}$ and $\mathbf{D}_{\mathrm{yv}}$ should be so selected as to achieve the proper weighting in the following cost functional:

$$
\begin{gathered}
\mathrm{J}_{\gamma}(\mathbf{x}, \mathrm{v}, \mathrm{w})=\|\mathbf{y}(\mathrm{t})\|_{2}^{2}-\gamma^{2}\|\mathrm{w}(\mathrm{t})\|_{2}^{2}= \\
=\int_{0}^{\infty}\left(\mathbf{y}^{\mathrm{T}}(\mathrm{t}) \mathbf{y}(\mathrm{t})-\gamma^{2} \mathrm{w}^{2}(\mathrm{t})\right) \mathrm{dt}
\end{gathered}
$$

where $\gamma>0$ is a properly chosen constant (see below) called the performance bound.

The last two conditions of (9) are assumed to avoid cross terms in the functional (10) so that to get an equivalence to the corresponding Lqr criterion, i.e.:

$$
\mathbf{Q}=\mathbf{C}_{\mathrm{y}}^{\mathrm{T}} \mathbf{C}_{\mathrm{y}}, \mathbf{R}=\mathbf{D}_{\mathrm{yv}}^{\mathrm{T}} \mathbf{D}_{\mathrm{yv}}=\mathbf{I}
$$

(compare (33), (34))

We have defined a differential game of two players where each of them is trying to influence the system by proper (profitable for him) choice of his strategy $-\mathrm{v}$ and $\mathrm{w}$, respectively.

We (as the first player) are trying to minimize (10) with respect to $\mathrm{v}$ while the disturbances (the second player) is assumed to maximize the cost (10).

Assuming the commutativity of min-max operators as well as that the optimal strategies $\mathrm{v}^{*}, \mathrm{w}^{*}$ of both parties exist we have:

$$
\min _{\mathrm{v}} \max _{\mathrm{w}} \mathrm{J}_{\gamma}(\mathbf{x}, \mathrm{v}, \mathrm{w})=\mathrm{J}_{\gamma}\left(\mathbf{x}, \mathrm{v}^{*}, \mathrm{w}^{*}\right)
$$

Let's observe that minimization of the maximized, by the second player, cost (10) refers to the situation where we are doing our best (optimally stabilizing the system output) assuming the worst-case realization of system disturbances.

One can prove [3] that if for a given $\gamma>0 \mathrm{w}^{*}$ maximizing the cost (10) exists, this fact can be interpreted in terms of the condition:

where:

$$
\left\|\mathrm{G}_{\mathrm{yw}}(\mathrm{K})\right\|_{\infty}<\gamma
$$

$\mathrm{K}$ - applied controller which denotes boundedness of the infinity norm of the closed-loop transfer function $\mathrm{G}_{\mathrm{yw}}$ from the disturbances $\mathrm{w}(\mathrm{t})$ to the output $\mathrm{y}(\mathrm{t})$. This guarantees also the system $\mathrm{L}_{2}$-gain stability (from $\mathrm{w}$ to $\mathrm{y}$ ) [1]. 
Minimization of (10) with respect to v, under assumption that the minimal bound $\gamma$ of is obtained, allows in turn to find the optimal controller $\mathrm{K}^{*}$.

The explanations can be summarized into the following condition:

where:

$$
\min _{\mathrm{K} \in \mathrm{K}}\left\|\mathrm{G}_{\mathrm{yw}}(\mathrm{K})\right\|_{\infty}=\left\|\mathrm{G}_{\mathrm{yw}}\left(\mathrm{K}^{*}\right)\right\|_{\infty}=\gamma^{*}
$$

$\gamma^{*}-$ the smallest $\gamma$ in the condition

$\mathrm{K}$ - a set of available controllers.

The formulas for suboptimal strategies are $[3,1]$ :

$$
\begin{aligned}
\mathrm{v}(\mathrm{t}) & =-\mathbf{B}_{\mathrm{v}}^{\mathrm{T}} \mathbf{P}(\mathrm{t}) \mathbf{x}(\mathrm{t}) \\
\mathrm{w}(\mathrm{t}) & =\gamma^{-2} \mathbf{B}_{\mathrm{w}}^{\mathrm{T}} \mathbf{P}(\mathrm{t}) \mathbf{x}(\mathrm{t})
\end{aligned}
$$

where matrix $\mathrm{P}(\mathrm{t})$ is a solution of the $\mathrm{H} \infty$-like algebraic Riccati equation (RE),

$$
\begin{gathered}
\mathbf{P A}+\mathbf{A}^{\mathrm{T}} \mathbf{P}-\mathbf{P}\left(\mathbf{B}_{\mathrm{v}} \mathbf{B}_{\mathrm{v}}^{\mathrm{T}}-\gamma^{-2} \mathbf{B}_{\mathrm{w}} \mathbf{B}_{\mathrm{w}}^{\mathrm{T}}\right) \mathbf{P}+ \\
+\mathbf{C}_{\mathrm{y}}^{\mathrm{T}} \mathbf{C}_{\mathrm{y}}=\mathbf{0}
\end{gathered}
$$

such that:

$$
\mathbf{A}-\left(\mathbf{B}_{\mathrm{v}} \mathbf{B}_{\mathrm{v}}^{\mathrm{T}}-\gamma^{-2} \mathbf{B}_{\mathrm{w}} \mathbf{B}_{\mathrm{w}}^{\mathrm{T}}\right) \mathbf{P}
$$

is stable, i.e. all of the eigenvalues of this matrix have negative real parts.

In practice, to solve the above formulated problem, we have to use some iterative procedure which consists in repeating the required calculations for different values of $\gamma$ in order to choose the smallest one. For the properly selected $\gamma$ (i.e. for $\gamma=\gamma^{*}$ ) the strategies (15) are optimal.

\section{COURSE-KEEPING PROBLEM AND THE NORRBIN'S SHIP MODEL STRUCTURE}

The problem of course-keeping is a task of designing an automatic control aid (autopilot) which is able, by using appropriate rudder actions, to control the ship motion as to maintain a pre-assigned constant heading. This problem is often considered as consisting of two sub-problems. The first one concerns the ship controlling along the straight line at small course deviations. The second problem concerns the proper ship control during large manoeuvres, i.e. the problem of quality of transition process as a reply for a course step-change.

In order to synthesize a course-keeping controller we apply the following Norrbin's [7, 12] ship model general structure:

$$
\mathrm{T} \ddot{\psi}+\mathrm{F}(\dot{\psi})=\mathrm{k} \delta
$$

where:

$\psi \quad-$ actual ship course angle (heading)

$\delta \quad-$ rudder deflection angle as a control variable

$\mathrm{T}, \mathrm{k}$ - unknown model parameters

$\mathrm{F}(\cdot) \quad-$ unknown function with assumed structure

In the 'classical' approach to ship control the structure of the nonlinear function $\mathrm{F}$ is (according to Norrbin model) often assumed in the form of a polynomial of the third order. Generally it may be assumed as follows:

$$
\mathrm{F}(\dot{\psi})=\mathrm{a}_{3} \dot{\psi}^{3}+\mathrm{a}_{2} \dot{\psi}^{2}+\mathrm{a}_{1} \dot{\psi}+\mathrm{a}_{0}
$$

For the ship with hull symmetry we have $a_{2}=0$. The bias term $\mathrm{a}_{0}$ is frequently taken as null, being conveniently treated as an additional rudder-offset which can be made null by the adequate selection of the integral action in the autopilot design.
The most commonly used structure has therefore the form:

$$
\mathrm{F}(\dot{\psi})=\mathrm{a}_{3} \dot{\psi}^{3}+\mathrm{a}_{1} \dot{\psi}
$$

Now, assuming that the structure of the function $\mathrm{F}$ has been predetermined the coefficients $a_{i}$ are usually identified during sea trials [12]. After some ship-circulation tests we apply regression analysis to the obtained data ( $\dot{\psi}$ in function of $\delta$ ), for each of the mentioned structures separately, and then we search for the best fitting solution.

Since each of the tests should be performed for prescribed sailing conditions, e.g. different ship load, trim and velocity it follows that the problem of sufficiently general model building is a laborious and expensive task. For this reason in practice linear models are preferred [14] as being simpler for identification as well as we have, in this case, a number of linear synthesis methods at our disposal. For several control tasks however, especially for strongly nonlinear objects, the linear models are insufficient. The control algorithm obtained from such model leads not only to the deterioration of control performance but may also produce an unpredictable destabilization of system. Due to the above mentioned facts we propose an approach which, while dealing with nonlinear models, avoids, at the same time, to cope with the demanding identification task.

\section{ROBUST SHIP AUTOPILOT DESIGN}

In this section, based on the above given theoretical facts as well as on the presented Norrbin's model structure, we formulate and then solve the problem of robust ship coursekeeping control synthesis. It is assumed, for simplicity (but without loss of generality), that the desired (reference) course value equals to zero: $\psi_{\mathrm{d}}=0$.

\section{The case without additional load disturbances}

To apply the above mentioned theory let us first define the course-keeping problem as a differential game. To this end we rewrite the Norrbin's model (18) in the state space form:

$$
\begin{gathered}
\dot{\psi}=\mathrm{r} \\
\mathrm{r}=\Phi(\mathrm{r})+\mathrm{c} \delta
\end{gathered}
$$

where:

$\Phi=-\mathrm{F}(\cdot) / \mathrm{T}$,

$\mathrm{c}=\mathrm{k} / \mathrm{T}$

$r$ - course turning rate (angular velocity).

According to (20) the function $\Phi$ is:

$$
\Phi(\dot{\psi})=\mathrm{b}_{3} \dot{\psi}^{3}+\mathrm{b}_{1} \dot{\psi}
$$

where:

$\mathrm{b}_{\mathrm{i}}=\mathrm{a}_{\mathrm{i}} / \mathrm{T}, \mathrm{i}=1,3$

To make use of simple feedback linearization method we apply (compare (6)) the controller:

$$
\delta=\frac{-\hat{\Phi}+\mathrm{v}}{\hat{\mathrm{c}}}=\frac{-\left(\hat{\mathrm{b}}_{3} \dot{\psi}^{3}+\hat{\mathrm{b}}_{1} \dot{\psi}\right)+\mathrm{v}}{\hat{\mathrm{c}}}
$$

Now, following the procedure given in section 2 , we can write Eq. (21) in the form:

$$
\begin{gathered}
\dot{\psi}=\mathrm{r} \\
\dot{\mathrm{r}}=\mathrm{v}+\underbrace{\left\{\left(\mathrm{b}_{3}-\hat{\mathrm{b}}_{3}\right) \dot{\psi}^{3}+\left(\mathrm{b}_{1}-\hat{\mathrm{b}_{1}}\right) \dot{\psi}+(\mathrm{c}-\hat{\mathrm{c}}) \delta\right.}_{\mathrm{w}}\}
\end{gathered}
$$


or simply as follows:

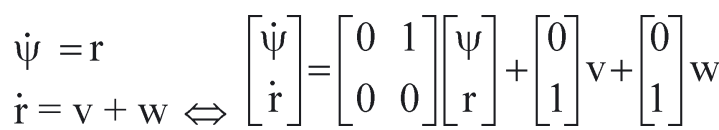

where $\mathrm{w}$ denotes errors caused by the model parameter uncertainty (considered here as a control strategy of the opposing nature).

The system output may be assumed as follows:

$$
\mathbf{y}=\left[\begin{array}{l}
\mathrm{y}_{1} \\
\mathrm{y}_{2}
\end{array}\right]=\left[\begin{array}{ll}
\lambda & 0 \\
0 & 0
\end{array}\right]\left[\begin{array}{l}
\psi \\
\mathrm{r}
\end{array}\right]+\left[\begin{array}{l}
0 \\
1
\end{array}\right] \mathrm{v}=\left[\begin{array}{c}
\lambda \psi \\
\mathrm{v}
\end{array}\right]
$$

where the constant $\lambda$ is a criterion weight.

The matrices which define the system in question are as follows:

$$
A=\left[\begin{array}{ll}
0 & 1 \\
0 & 0
\end{array}\right], \mathbf{B}_{\mathrm{v}}=\mathbf{B}_{\mathrm{w}}=\left[\begin{array}{l}
0 \\
1
\end{array}\right], \mathbf{C}_{\mathrm{y}}=\left[\begin{array}{ll}
\lambda & 0 \\
0 & 0
\end{array}\right], \mathbf{D}_{\mathrm{yv}}=\left[\begin{array}{l}
0 \\
1
\end{array}\right]
$$

Let's note that by the proper choice of the output matrices $\mathbf{C}_{\mathrm{y}}, \mathbf{D}_{\mathrm{yv}}$ a desired cost criterion (compare (11)) is obtained.

To find the proper numerical solution $\mathbf{P}(\mathrm{t})$ of Riccati-like equation (16) we can use Matlab function care [6] for different values of the constant $\gamma>0$. As we want to select $\gamma$ to be minimal (provided the solution RE exists) we have to apply this procedure repeatedly. This way we get the proper control strategy (see (15)) which will be used later in the process simulation.

\section{The case with added load disturbances}

During the routine work of the autopilot (i.e. under specified steady-state conditions, e.g. straight route mode) besides modelling errors we have also to take into account the load disturbances. The disturbances lead to the steady heading error which can be typically compensated by integral action introduced to the control system.

To cope with the steady-state error we will consider in this section the problem of robust regulator design equipped with integral action.

Let us first define an extra error in the form of integral of the course error:

$$
\mathrm{e}=\int_{0}^{\mathrm{t}} \psi \mathrm{dt}
$$

Based on the model (25) we define the augmented system by adding the error equation (28) (written in differential form):

$$
\begin{aligned}
& \dot{\psi}=\mathrm{r} \\
& \dot{\mathrm{r}}=\mathrm{v}+\mathrm{w}+\mathrm{d} \\
& \dot{\mathrm{e}}=\psi
\end{aligned} \Leftrightarrow\left[\begin{array}{c}
\dot{\psi} \\
\dot{\mathrm{r}} \\
\dot{\mathrm{e}}
\end{array}\right]=\left[\begin{array}{lll}
0 & 1 & 0 \\
0 & 0 & 0 \\
1 & 0 & 0
\end{array}\right]\left[\begin{array}{l}
\psi \\
\mathrm{r} \\
\mathrm{e}
\end{array}\right]+\left[\begin{array}{l}
0 \\
1 \\
0
\end{array}\right] \mathrm{v}+\left[\begin{array}{l}
0 \\
1 \\
0
\end{array}\right] \mathrm{w}+\left[\begin{array}{l}
0 \\
1 \\
0
\end{array}\right] \mathrm{d}(
$$

where $\mathrm{d}$ are constant or slowly varying load disturbances.

The complementary output equation is:

$$
\mathbf{y}=\left[\begin{array}{l}
\mathrm{y}_{1} \\
\mathrm{y}_{2} \\
\mathrm{y}_{3}
\end{array}\right]=\left[\begin{array}{lll}
\lambda & 0 & 0 \\
0 & 0 & 0 \\
0 & 0 & 1
\end{array}\right]\left[\begin{array}{l}
\psi \\
\mathrm{r} \\
\mathrm{e}
\end{array}\right]+\left[\begin{array}{l}
0 \\
1 \\
0
\end{array}\right] \mathrm{v}=\left[\begin{array}{c}
\lambda \psi \\
\mathrm{v} \\
\mathrm{e}
\end{array}\right]
$$

Thus the matrices that define our system are as follows:

$$
\mathbf{A}=\left[\begin{array}{lll}
0 & 1 & 0 \\
0 & 0 & 0 \\
1 & 0 & 0
\end{array}\right], \mathbf{B}_{\mathrm{v}}=\mathbf{B}_{\mathrm{w}}=\left[\begin{array}{l}
0 \\
1 \\
0
\end{array}\right], \mathbf{C}_{\mathrm{y}}=\left[\begin{array}{lll}
\lambda & 0 & 0 \\
0 & 0 & 0 \\
0 & 0 & 1
\end{array}\right], \mathbf{D}_{\mathrm{yv}}=\left[\begin{array}{l}
0 \\
1 \\
0
\end{array}\right]
$$

Let's notice that during controller synthesis process the disturbances $\mathrm{d}$ are not directly taken into account. However, thanks to above presented system structure, any appearance of disturbances during system operation leads to controller counteraction which prevents steady-state error.

\section{COURSE-CHANGING PROCESS SIMULATIONS}

The standard method of assessing the control system quality is based on analysis of the transition process as a response to the step input. Thus in the following simulations we will test the ship behaviour after step change of the course set-point under different controller structures as well as various criteria data.

\section{Ship simulation model}

According to [15] we assume, as the actual parameters of the ship model (21), the dynamic manoeuvring parameters of the $\mathrm{m} / \mathrm{s}$ Compass Island. The units of time, length and angle are one minute, one nautical mile and one radian, respectively. The parameters were determined as follows:

$$
\begin{gathered}
b_{3}=-0.62 \mathrm{~min}, b_{1}=-1.064 \mathrm{~min}^{-1}, \\
b_{2}=b_{0} \cong 0, c=3.553 \mathrm{rad} / \mathrm{min}
\end{gathered}
$$

The parameters are, of course, not known to the control system designer thereby during the process simulations we will take another set of their values - possibly, substantially different.

It is assumed also that the ship's velocity during the steadystate control process phase is constant $\mathrm{u}=0.25 \mathrm{~nm} / \mathrm{min}$ and that all the time we have constant propelling force.

The ship has the following characteristics: the maximum rudder angle is 35 deg., gross register tonnage of 9214 RT, deadweight of $13498 \mathrm{t}$, length of $172 \mathrm{~m}$., draught of $9.14 \mathrm{~m}$, one propeller, and maximum speed of $20 \mathrm{kn}$. Let's note that the assumed parameters make the ship directionally stable [12,14] but we can get similar results for the ship which is directionally unstable (e.g. for the opposite sign of the coefficient $b_{1}$, i.e. $\left.b_{1}=-1.064 \mathrm{~min}^{-1}\right)$.

\section{Simulation results}

In order to examine the performance of the robust controller in question a corresponding Lqr regulator [3] has also been tested for comparison. The matching criteria matrices for the two cases were chosen the same.

As an approximate counterpart values to the actual ship parameters (32) (unknown for designer) we assume:

$$
\begin{gathered}
\hat{\mathrm{b}}_{3}=-1 \mathrm{~min}, \hat{\mathrm{b}}_{1}=-2 \mathrm{~min}^{-1}, \\
\hat{\mathrm{b}}_{2}=\hat{\mathrm{b}}_{0} \cong 0, \hat{\mathrm{c}}=2 \mathrm{rad} / \mathrm{min}
\end{gathered}
$$

The parameters are essential for the controller design as they contain some uncertain data of the ship's dynamics.

The remaining numerical data are as follows:

$$
\gamma^{*}=1.05, \lambda=2
$$

and

$$
\mathbf{Q}=\left[\begin{array}{ll}
\lambda^{2} & 0 \\
0 & 0
\end{array}\right], \quad \mathbf{R}=1
$$

where the criteria matrices $\mathbf{Q}$ and $\mathbf{R}$ refer to the corresponding Lqr problem. Let's notice that the matrices are exactly the same as those which occur in the matching robust case (compare (26)). 
a)

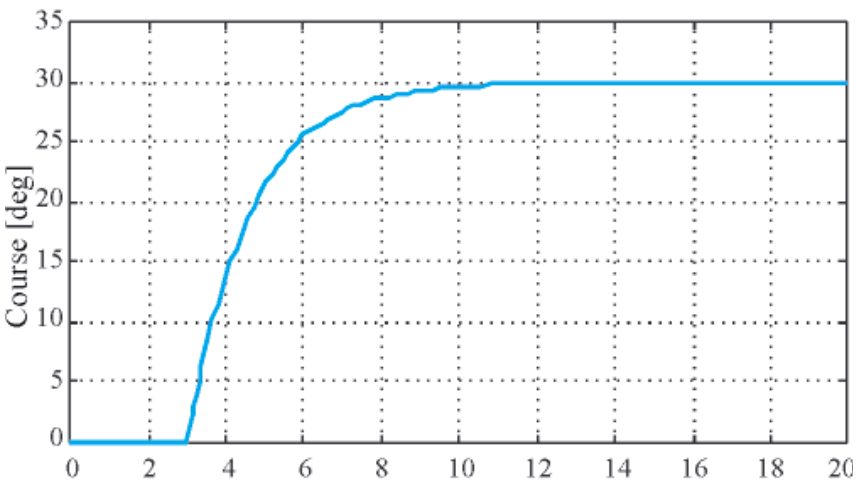

b)

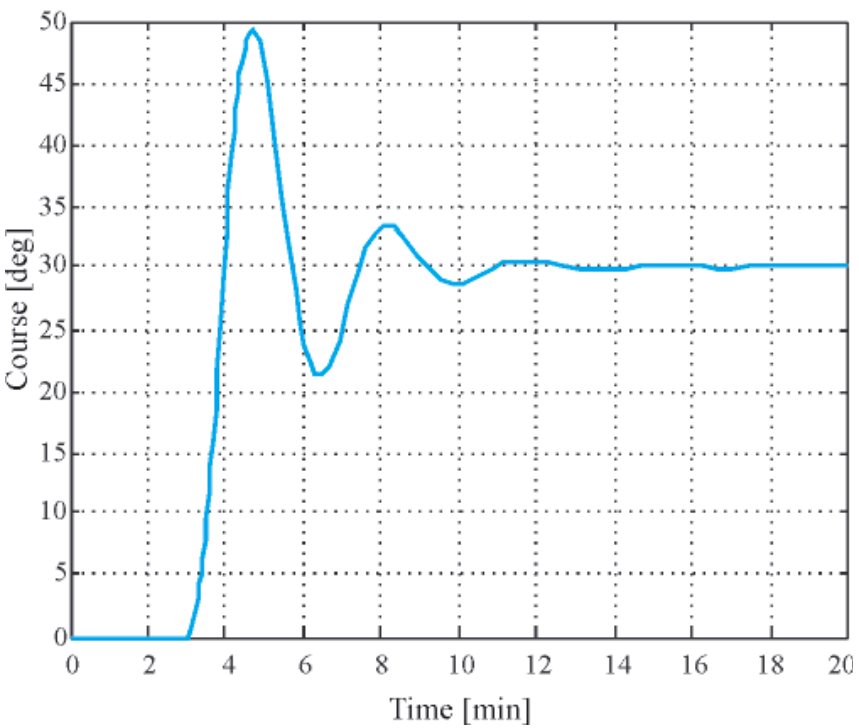

Fig. 1. Ship headings versus time for: a) robust controller, b) Lqr regulator $\left(30^{\circ}\right.$ turning)

The following figures show the situation where the ship is moving for $3 \mathrm{~min}$ with steady speed $(0.25 \mathrm{~nm} / \mathrm{min})$ along a straight line and then we apply a 30-degree step heading change command (in the case given in Fig. 3 and $4 \mathrm{a}$ disturbing torque is additionally applied).

The graphs presented in Fig. 1 and 2 show respectively the plots of headings and rudder deflections versus time for: a) robust controller, b) Lqr regulator.

In Fig. 3 and 4 are presented corresponding plots but for the case where the controllers are provided with integral action.

Let's notice that despite the fact that the order of parameter errors is here about $100 \%$ the robust controller performance (Fig. 1a) is very good. On the other hand the corresponding Lqr controller operates close to the stability margin (see Fig. 1b).

Moreover, according to the author experience, the plantmodel parameter errors for the robust controller can be made substantially higher without noticeable process performance degradation.

Fig. 3 and 4 show corresponding graphs, however, with the difference that the controllers: robust and Lqr one are now equipped with integral action. The intensity of the constant load disturbances d acting on the ship, in the form of torque, corresponds to the compensating deflection of the rudder by $11 \mathrm{deg}$ (see Fig. 4).

The numerical data for this case are as follows:

$$
\gamma^{*}=1.2, \lambda=7
$$

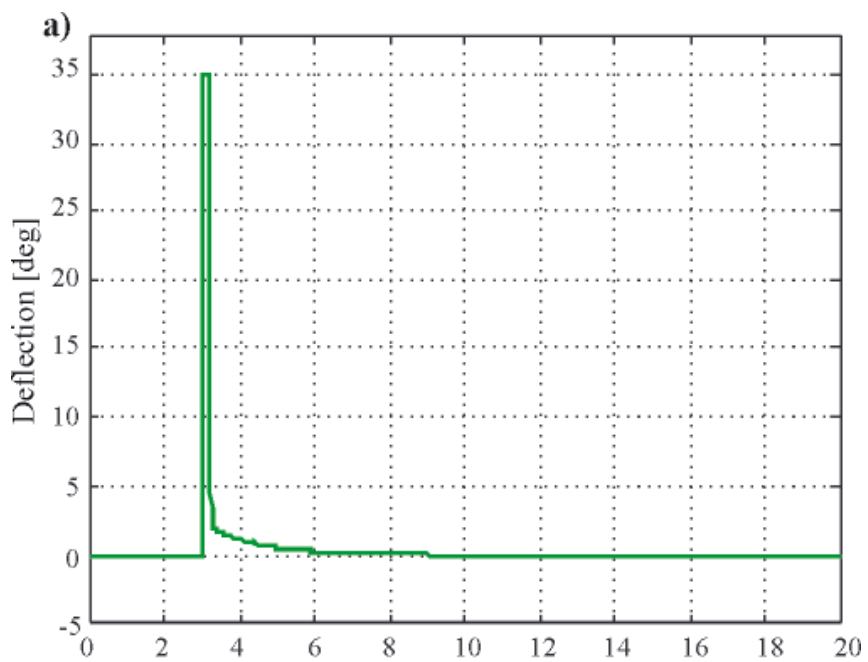

b)

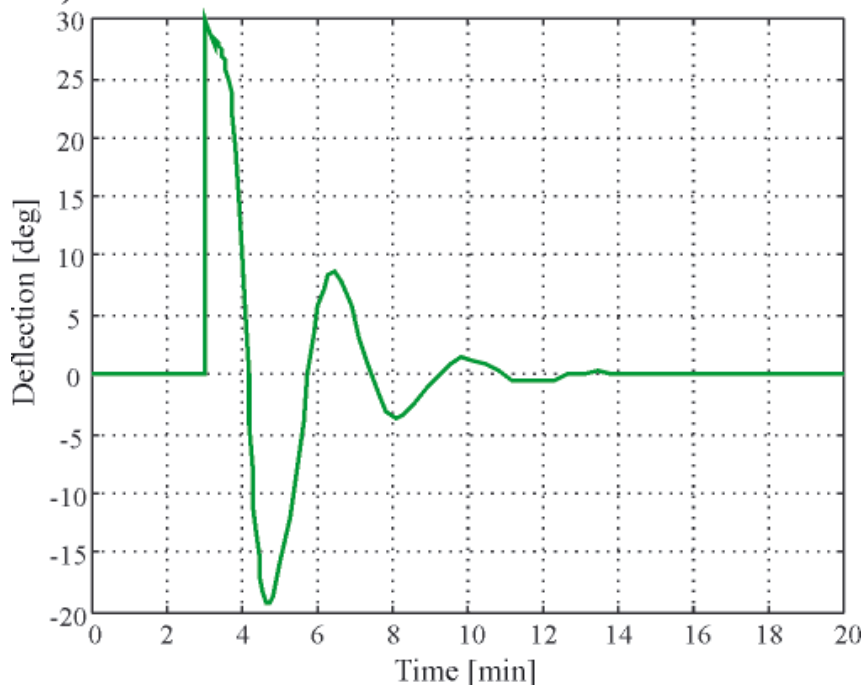

Fig. 2. Rudder deflections for: a) robust controller b) Lqr regulator ( $30^{\circ}$ turning)

and

$$
\mathbf{Q}=\left[\begin{array}{lll}
\lambda^{2} & 0 & 0 \\
0 & 0 & 0 \\
0 & 0 & 1
\end{array}\right], \mathbf{R}=1
$$

where the criteria matrices $\mathbf{Q}$ and $\mathbf{R}$ refer, as before, to the corresponding Lqr problem.

As it can be seen, also in this case the robust controller performance is still better than its Lqr counterpart.

Let's observe that the plant-model mismatch disturbances $w$ are diminishing with the progress of a transient phase of the process regulation (compare (24)). Thus the proper effect of integral action is manifesting itself during the system steadystate, i.e. just after the process transient phase.

By manipulating the criteria weighting $\lambda$ we can adjust the required trade-off between precision of the output variable control $(\psi)$ in relation to the control effort (v) and/or the integral of course error (e).

Taking e.g. $\lambda=7$ we highly penalize the course error in relation to the control effort $\mathrm{v}$ as well as to the integral error e. To increase the number of degrees of freedom in this respect we could introduce some additional weighting related to the 


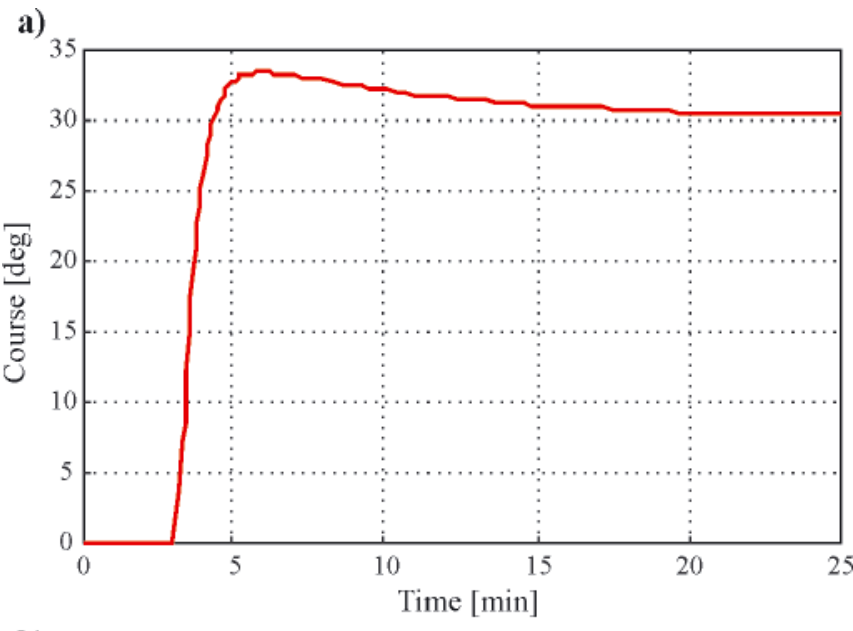

b)

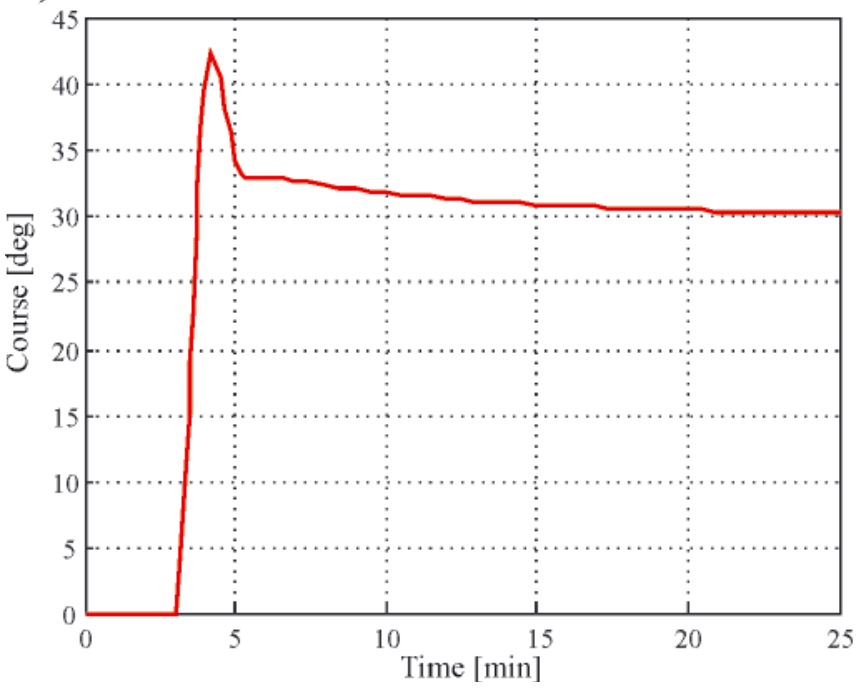

Fig. 3. Ship headings versus time for controllers with integral action a) robust controller, b) Lqr regulator $\left(30^{\circ}\right.$ turning)

state variable e. High penalization of this variable results in a rapid decrease of the course steady-state error, however, at the cost of increasing the course overshot.

\section{CONCLUSIONS}

The paper describes a proposition of a novel technique for robust control system design, which can be used to the ship motion control.

The technique seems to be very attractive for designing the ship autopilot albeit it requires additional research which should take into account different types of ship nonlinear models (e.g. including a steering gear) as well as consider various sailing conditions (in this phase of research the disturbances from waves has been deliberately omitted). It is worth noting that the modern adaptive PID controllers only partially solve the problem of ship model parameter changes. They can tune (as a rule) their gains only in response to the ship velocity changes while the number of factors responsible for the ship dynamic variations is much greater (e.g. ship load). The factors, when not taken into account by the controller, may lead to the degradation of steering process performance. Therefore, each new design proposal in this respect should attract attention.

The presented paper is focused on the properly formulated theory rather than on the practical engineering issues and is devised as a theoretical introduction to more practice-oriented engineering research.

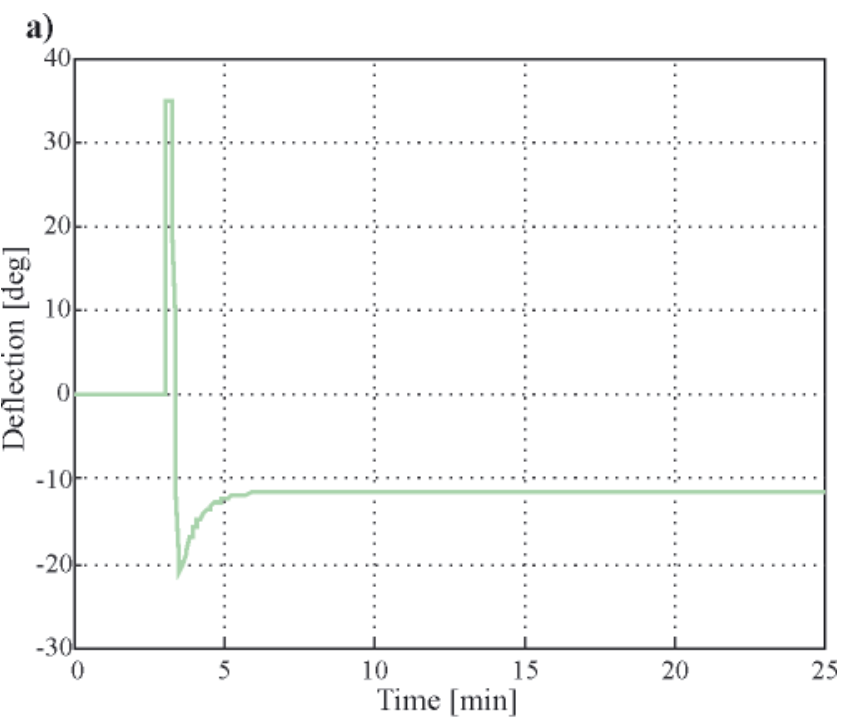

b)

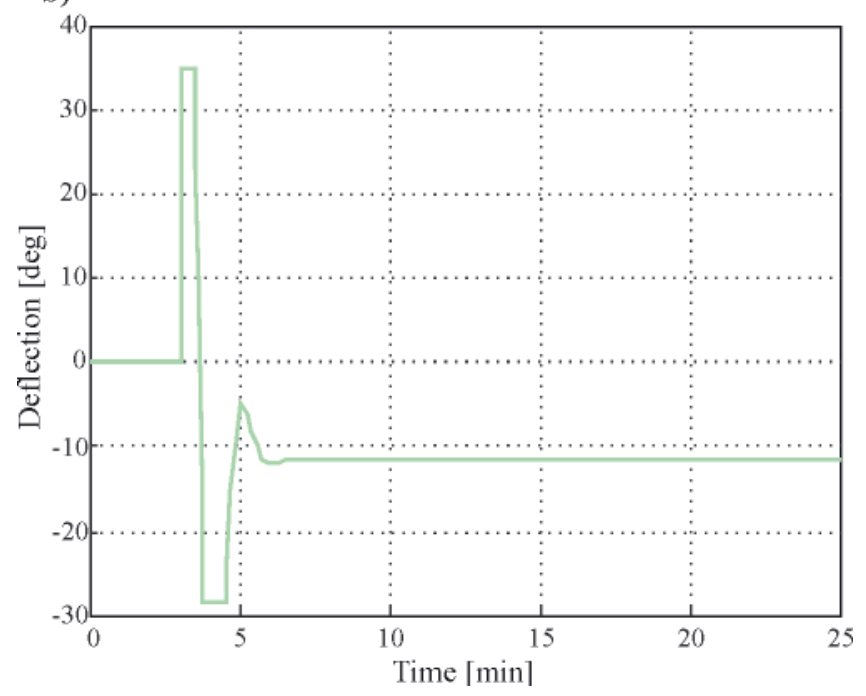

Fig. 4. Rudder deflections for controllers with integral action: a) robust controller, b) Lqr regulator ( $30^{\circ}$ turning)

\section{BIBLIOGRAPHY}

1. Abu-Khalaf M., Huang J., Lewis F. L.: Nonlinear Constrained Feedback Control. Advances in Industrial Control. Springer, London, 2006.

2. van Amerongen J.: Adaptive steering of ships. A model-reference approach to improved manoeuvring and economical course keeping. Ph.D. Thesis, Delft University of Technology, 1982.

3. Burl J. B.: Linear optimal control. Addison-Wesley, Menlo Park, CA, 1999.

4. Basar T., Bernhard P.: H⿻ - optimal control and related minimax design problems. A dynamic game approach. Birkhäuser, Berlin 1991.

5. Basar T., Olsder G.J.: Dynamic noncooperative game theory. SIAM Series in Classics in Applied Mathematics, Philadelphia, 1999.

6. Control System Toolbox User's Guide. For Use with MATLAB. The MathWorks, Inc. 1998.

7. Fossen T. I.: Guidance and control of ocean vehicles. John Wiley, Chichester, USA, 1994.

8. Isaacs R.: Differential games. John Wiley, New York 1965.

9. Isidori A.: Nonlinear Control Systems. An introduction, Springer -Verlag, Berlin, 1989.

10.Khalil H.K.: Nonlinear Systems. Prentice Hall, Upper Saddle River, NJ, 2002. 
11. Lewis F. W., Jagannathan S. and A. Yesildirak: Neural Network Control of Robot Manipulators and Non-Linear Systems. Taylor \& Francis, 1998.

12.Lisowski J.: Ship as an object of automatic control. Wyd. Morskie, Gdańsk 1981 (in Polish).

13.Márquez H. J.: Nonlinear control systems. Analysis and design. John Wiley, NJ, 2003.

14.Morawski L., Pomirski J.: Design of the robust PID coursekeeping control system for ships. Polish Maritime Research, No. $1,2002$.

15.de Wit C., Oppe J.: Optimal collision avoidance in unconfined waters. Journal of the Institute of Navigation, Vol. 3,126, No.4, $1979 / 80$.

16.Zwierzewicz Z.: On some geometric aspects of differential games (in Polish). Archives of Control Sciences, No. 3-4, 1985

17.Zwierzewicz Z.: Ship course-keeping via nonlinear adaptive control synthesis. Int. Journal of Factory Automation, Robotics and Soft Computing, 2007, no. 2, April, 2007, pp.102-107.
18.Zwierzewicz Z.: Methods and algorithms of ship automatic control systems (in Polish). Scientific publishing of Szczecin Maritime University, Szczecin 2012

\section{CONTACT WITH THE AUTHOR}

Zenon Zwierzewicz, Assoc. Prof. Faculty of Marine Engineering Maritime University of Szczecin Wały Chrobrego 1-2 70-500 Szczecin, POLAND e-mail: ieiao@am.szczecin.pl 